\title{
勇揧天文研究新高峰 建设世界一流天文台
}

常进

中国科学院国家天文台, 北京 100101

E-mail: changjin@nao.cas.cn

\section{Scaling new heights in astronomical research, and constructing a world- class observatory}

Jin Chang

National Astronomical Observatories, Chinese Academy of Sciences, Beijing 100101, China E-mail: changjin@nao.cas.cn

doi: 10.1360/TB-2021-0254

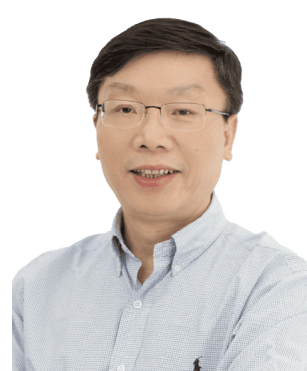

\section{常进}

中国科学院国家天文台台长、 中国科学院暗物质与空间天文 重点实验室主任、中国科学技 术大学天文与空间科学学院院 长. 2019年当选为中国科学院 院士。长期从事空间高能粒子 尤其是电子的探测技术方法及 科学实验研究, 为“悟空”号暗 物质粒子探测卫星首席科学家.
2021年，中国共产党喜迎建党100周年，中国科学院国家天文台(简称国家天文 台)也迎来组建 20 周年.征程波澜壮阔,初心历久弥坚. 20 年来, 国家天文台在坚持面 向世界科技前沿基础上，积极投身国家重大战略发展，坚持“民主办台、开放兴台、 人才强台”发展战略和“出创新成果、出创新人才、出创新思想”总体目标, 肩扛国 家战略科技力量使命, 全面、协调、快速、持续发展, 取得了一系列重大创新成果, 正建设成为世界一流的综合性天文研究机构.

1998年，中国科学院启动知识创新工程. 为凝练我国天文科技目标、调整天文 学科技布局，中国科学院决定在原天文台系统的“五台三站一中心”基础上组建国家 天文台. 1999年4月, 国家天文观测中心成立, 确立了宇宙大尺度结构等九大研究领 域，重点支持兴隆等五大观测基地和 28 个创新研究团组，形成了国家天文台维形. 2001年3月27日，中央机构编制委员会办公室批复同意成立中国科学院国家天文台， 云南天文台、南京天文光学技术研究所、新疆天文台(原乌鲁木齐天文站, 2011年1 月更名为现名) 和长春人造卫星观测站成为国家天文台直属单位. 紫金山天文台、 上海天文台继续保留中国科学院院直属事业单位法人资格, 是国家天文台组成 单位.

天文学是当代自然科学的核心前沿学科之一。宇宙起源和演化、暗物质、暗 能量、引力波、地外生命等无不是天文学研究的重要领域. 天文观测挑战技术极 限，是高精尖技术创新源头之一和“卡脖子”关键技术攻关的最前线. 天文学还支撑 着国家深空探测和空天安全, 服务着国计民生和人类福祉。

国家天文台组建以来的 20 年，也是中国天文学快速发展的 20 年. 20 年披荆斩 棘、风雨兼程. 国家天文台已发展成为集天文学基础前沿研究、天文技术方法创 新及应用、重大观测装置建造与运行、国家月球与深空探测科学应用和国家空间 碎片监测与应用四位一体的综合性天文研究机构, 已成为中国天文学事业发展的 中坚力量.

在勇攀世界科技前沿方面, 国家天文台高水平建成和运行了以郭守敬望远镜 
(Large Sky Area Multi-object Fiber Spectroscopic Telescope, LAMOST)、中国天眼(Five-hundred-meter Aperture Spherical radio Telescope, FAST)为代表的一批国际领先的重要观测设备. 在宇宙大尺度结构、银河系结构和演化 历史、恒星和致密天体、系外行星、太阳物理等领域取得了一批有影响力的重要科学成果.

在投身国家重大战略方面, 国家天文台承担了载人航天与探月工程、首次火星探测任务、空间科学卫星工 程、转发式卫星导航试验系统、空间碎片监测与应用、空间基准等重大科技任务, 为推动载人登月、深空探测、 脉冲星导航、空间态势感知和太空安全等方面的研究作出了重要贡献, 已成为国家空间探测和空天安全领域不可 替代的重要方面军.

国家天文台建有光学天文、太阳活动、月球与深空探测、空间天文与技术、计算天体物理、天文光学技 术、天体结构与演化、FAST 重点实验室等8个中国科学院重点实验室, 并与 20 余所大学、科研机构或高新技术企 业建立了战略合作关系。国家天文台在北京密云、怀柔, 天津武青, 河北兴隆, 云南昆明风凰山、抚仙湖、丽江, 新 疆南山、奇台、喀什、红柳峡、乌拉斯台, 西藏阿里、羊入井, 内蒙古明安图, 贵州平塘, 海外的阿根廷、智利等 地建有观测台站. 国家天文科学数据中心、国家航天局空间碎片监测与应用中心、中国科学院天文大科学研究中 心、中国科学院南美天文研究中心依托国家天文台建设.

人才始终是天文学和国家天文台发展的生命线. 20 年来，国家天文台凝聚和培养了一批涵盖天文学各领域的 优秀人才和领军人物, 在相关领域积极发挥“领头羊”作用, 也涌现出“人民科学家”“时代楷模”南仁东这样的杰出科 学家.

值国家天文台组建20周年之际，《科学通报》组织出版专辑，邀请了国家天文台李菂、赵永恒、詹虎、刘继 峰、韩金林、王杰、赵公博、刘超、颜毅华、陈学雷等优秀科研人员撰稿, 系统展示 20 年来国家天文台在各领域 取得的重要科研进展. 专辑发表了11篇文章, 内容包括FAST早期科学及前景展望 ${ }^{[1]}$ 、 LAMOST的科技创新 ${ }^{[2]}$ 、载 人航天工程巡天空间望远镜 ${ }^{[3]}$ 、暗物质粒子探测卫星研究进展 ${ }^{[4]}$ 、恒星级黑洞的搜寻与研究进展 ${ }^{[5]}$ 、中德 $6 \mathrm{~cm}$ 银 道面偏振巡天的发现 ${ }^{[6]}$ 、暗晕内部结构的数值模拟研究 ${ }^{[7]}$ 、斯隆数字巡天研究成果 ${ }^{[8]}$ 、银河系结构演化研究进 展 $^{[9]}$ 、太阳物理研究 20 年 $^{[10]}$ 以及天籁与鸿蒙实验 ${ }^{[1]}$.

出版该专辑既是对国家天文台过去20年各项重要研究进展的集中展示, 同时也是对我国当代天文学发展的热 点问题和未来发展进行学术交流与探讨, 希望为推动我国天文学跨越式发展及培养高水平创新性人才作出新的更 大贡献.

特别感谢《科学通报》对专辑出版的大力支持! 对所有作者、审稿人及编辑部工作人员的大力支持表示衰心 感谢!

\section{参考文献}

1 Li D, Wang P, Zhang Y K. Shining on from the first light: The early sciences of FAST (in Chinese). Chin Sci Bull, 2021, 66: 1272-1280 [李菂, 王 培, 张永坤. 从“初光”开始: FAST早期科学及前景展望. 科学通报, 2021, 66: 1272-1280]

2 Zhao Y H. Innovations in science and technology with the LAMOST (in Chinese). Chin Sci Bull, 2021, 66: 1281-1289 [赵永恒. LAMOST的科技 创新. 科学通报, 2021, 66: 1281-1289]

3 Zhan H. The wide-field multiband imaging and slitless spectroscopy survey to be carried out by the Survey Space Telescope of China Manned Space Program (in Chinese). Chin Sci Bull, 2021, 66: 1290-1298 [詹虎. 载人航天工程巡天空间望远镜大视场多色成像与无缝光谱巡天. 科学 通报, 2021, 66: 1290-1298]

4 Yuan Q, Chang J. Research progress of Dark Matter Particle Explorer (in Chinese). Chin Sci Bull, 2021, 66: 1299-1306 [袁强, 常进. 暗物质粒子 探测卫星研究进展. 科学通报, 2021, 66: 1299-1306]

5 Wang S, Liu J F, Zhang H T, et al. Search and research advances on stellar-mass black holes (in Chinese). Chin Sci Bull, 2021, 66: 1307-1314 [王 松, 刘继峰, 张昊䑣, 等. 恒星级黑洞的搜寻与研究进展. 科学通报, 2021, 66: 1307-1314]

6 Gao X Y, Sun X H, Han J L, et al. Scanning the Milky Way for 10 years: Discoveries from the Sino-German 6 cm polarization survey of the Galactic plane (in Chinese). Chin Sci Bull, 2021, 66: 1315-1326 [高旭阳, 孙晓辉, 韩金林, 等. 十年描银河: 中德6 cm银道面偏振巡天的发现. 科学通报, 2021, 66: 1315-1326] 
7 Wang J. The density profile of dark matter haloes with numerical simulation (in Chinese). Chin Sci Bull, 2021, 66: 1327-1335 [王杰. 通过数值模 拟技术探索暗物质晕的密度轮廓. 科学通报, 2021, 66: 1327-1335]

8 Wang Y T, Zhao G B. Cosmology with galaxy redshift surveys: Probing dark energy (in Chinese). Chin Sci Bull, 2021, 66: 1336-1345 [王钰婷, 赵 公博. 星系红移巡天宇宙学——探索暗能量. 科学通报, 2021, 66: 1336-1345]

9 Liu C. Progress on the structure and evolution of the Milky Way based on LAMOST survey (in Chinese). Chin Sci Bull, 2021, 66: 1346-1362 [刘 超. 基于LAMOST巡天的银河系结构演化研究新进展. 科学通报, 2021, 66: 1346-1362]

10 Yan Y H. Research advances in solar physics at National Astronomical Observatories of Chinese Academy of Sciences (in Chinese). Chin Sci Bull, 2021，66: 1363-1384 [颜毅华. 中国科学院国家天文台太阳物理研究20年. 科学通报, 2021, 66: 1363-1384]

11 Chen X L. Exploring the $21 \mathrm{~cm}$ cosmology: The Tianlai and Hongmeng experiments (in Chinese). Chin Sci Bull, 2021, 66: 1385-1398 [陈学雷. $21 \mathrm{~cm}$ 宇宙学的探索——天籁与鸿蒙实验. 科学通报, 2021, 66: 1385-1398] 